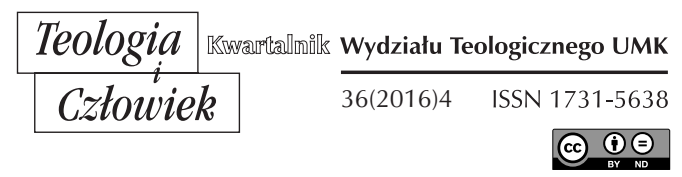

AGNIESZKA WYRĄBKIEWICZ*

TORUŃ

\title{
CRISTOLOGÍA DE SAN GREGORIO DE NISA. DOCTRINA Y CONTEXTO
}

DOI: http://dx.doi.org/10.12775/TiCz.2016.046

\section{INTRODUCCIÓN}

La elaboración de la doctrina cristológica en el pensamiento de los autores cristianos de los primeros siglos se presenta como un proceso complejo que oscila entre el deseo de guardar la ortodoxia respecto al magisterio apostólico por una parte y la vinculación con la tradición filosófica de la Grecia antigua por otra. La multiplicida de los elementos culturales, condicionamientos sociogeográficos y personales constituye un punto de partida para la construcción de muchas y, a menudo, muy originales concepciones cristológicas, entre las cuales vale la pena destacar

* Doktorantka nauk teologicznych III roku na Uniwersytecie Mikołaja Kopernika w Toruniu. Ukończyła studia teologiczne w 2012 roku na Wydziale Teologicznym Uniwersytetu Mikołaja Kopernika. W roku 2011 otrzymała stypendium Ministra Nauki i Szkolnictwa Wyższego. Zajmuje się duchową doktryną św. Grzegorza z Nyssy: koncepcją przebóstwienia człowieka, mistyczną teorią odkupienia oraz mistyką miłości (wyrabkiewicz@o2.pl). 
el pensamiento cristológico de san Greegorio de Nisa, un pensador muy especulativo y original, que sin embargo no escapa a los condicionamientos de su epoca. Los escritos de san Gregorio nos dejan vislumbrar una gran variedad de los factores que estimulan la creación de una doctrina, que toma por base una idea realista de la unidad del género humano ${ }^{1}$. Esta idea es la verdadera clave hermenéutica que permite una justa lectura de la cuestión de la „deificación” y la de la „humanización”, que rigen la exposición cristológica del autor ${ }^{2}$.

El presente trabajo intentará demostrar los principales elementos de la doctrina cristológica de san Gregorio, sobre todo arrojando luz sobre el mosaico de los diferentes influjos, que han contribuido significamete en la postura doctrinal del autor. Por esta causa la exposición de la cristología de Gregorio se expondrá en tres distintos aspectos: 1. Su contexto social, 2. Su contexto filosófico y 3. Su contexto psichológico.

\section{EL CONEXTO SOCIAL}

Como representante de la escuela alejandrina, en los pasajes de sus obras conagrados a Cristo, Gregorio pone el incapié en la manifestación de la Divinidad de Jesús. Esta postura resplandece sobre todo en su actividad apologética adoptada por nuestro autor después de la muerte de su famoso hermano, Basilio. La continuación acentuada de la tradición alejandrina queda de manifiesto principalmente en la argumentación y la terminología usada por el autora en su obra en tres tomos - Contra Eunomum. Combatiendo los errores de Eunomio, Gregorio presenta un alto grado de precisión lingüística. De este hecho su defensa de la igualdad del Padre y del Hijo se basa en dos vocablos: $\varphi \imath \lambda \alpha \nu \theta \rho \omega \pi i \alpha$ (filantropia) y $\alpha \dot{\alpha} \varepsilon v v \eta \sigma i \alpha$ (inengendrado). $\Phi \imath \lambda \alpha \nu \theta \rho \omega \pi i \alpha$ juga el papel de un argumento apologético. Por medio de este término Gregorio defiende la divinidad de Jesucristo frente a la postura de Eunomio, que confiesa la inferioridad

${ }^{1}$ Por. M. Przyszychowska, Wszyscy byliśmy w Adamie. Jedność ludzkości w Adamie w nauczaniu ojców Kościoła, Poznań 2013, s. 27.

${ }^{2}$ Por. L.F. Mateo-Seco, Chrystology, w: The Brill Dictionary of Gregory of Nyssa, red. L.F. Mateo-Seco, G. Maspero, Supplements to "Vigiliae Christianae" 99, Leiden 2010, s. 139. 
del Hijo de Dios respecto al Padre. La prueba de esta inferioridad se hubiera desvelado en la debilidad, manifestada en la Encarnación, y empujada hasta la kenosis del amor hacia los hombres ( $\left.\varphi \imath \lambda \alpha \nu \theta \rho \omega \pi^{i} \alpha\right)$, así que en el revestir la natura humana ${ }^{3}$. Para El Niceno, que considera que al Hijo de Dios no se le puede atribuir una naturaleza inferior respecto al Padre, siendo consubstancial con Él ${ }^{4}$, la $\varphi \imath \lambda \alpha \nu \theta \rho \omega \pi i ́ \alpha$, como causa de abajarse de Jesucristo hasta la condición humana, se convierte en la manifestación de la kenosis escogida deliberadamente por el Hijo. Además, Gregorio demuestra a Eunomio un error lógico, que se basa en el confundir la debilida, como consequencia del nacer en el tiempo y del asumir la naturaleza humana por el Hijo, con el amor en sí ( $\varphi \imath \lambda \alpha \nu \theta \rho \omega \pi i \alpha)$, así que en el refusar por esta causa la atribución del término $\varphi \imath \lambda \alpha \nu \theta \rho \omega \pi$ ó (el que quiere a los hombres) al Dios Padre ${ }^{5}$. El Niceno insiste, que no se puede dudar en el amor del Padre hacia los hombres, porque su amor respeco al

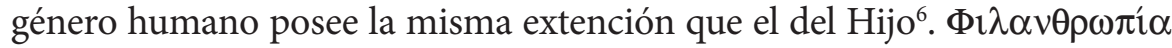
para Gregorio es par excellence un atributo de la naturaleza divina ${ }^{7}$. La misma Encarnación no constituye la causa de la separación del Hijo de la natural-

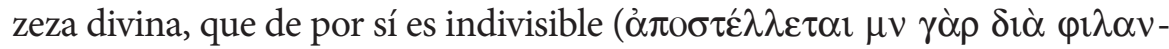

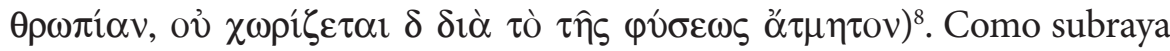
Hans Urs von Balthasar, en el mencionado enfrentamiento con Eunomio, el Capadocio esboza un modelo de la perfecta y mutua integración entre

${ }^{3}$ Por. Gregorius Nyssenus, Contra Eunomium III, Gregorii Nysseni Opera 2, red. W. Jaeger, Leiden 1960, s. 303.

${ }^{4}$ Por. S. Strękowski, Sofiologia św. Grzegorza z Nyssy: elementy teologii trynitarnej i antropologii w „Homiliach do Pieśni nad Pieśniami”, Kraków 2006, s. 127.

${ }^{5}$ Por. G. Maspero, Philantropia, w: The Brill Dictionary of Gregory of Nyssa, red. L.F. Mateo-Seco, G. Maspero, Supplements to "Vigiliae Christianae" 99, Leiden 2010, s. 598; H. Boersma, Embodiment and Virtue in Gregory of Nyssa. An Anagogical Approach, Oxford 2013, s. 162.

${ }^{6}$ Por. Gregorius Nyssenus, Contra Eunomium III, dz. cyt., s. 146.

7 Por. Gregorius Nyssenus, Oratio catechetica magna, Gregorii Nysseni Opera 3/4, red. E. Mühlenberg, Leiden 1996, s. 43.

${ }^{8}$ Por. Gregorius Nyssenus, De deitate Filii et Spiritus Sancti, Patrologia cursus completus. Series Graeca 46, red. J.P. Migne, Paris 1863, 561; tenże, Ad Ablabium quod non sint tres dei, Gregorii Nysseni Opera 3/1, red. F. Mueller, Leiden 1958, s. 46. 
el Padre y el Hijo9: el Hijo, estando en el Padre, - según este modelo posee una plena participación en todo esto que en la modalidad de ser posee el mismo Padre ${ }^{10}$. Como considera Walther Völker, tratando de la filantropía en la clave trinitario-historicosalvífica, el Niceno se inscribe de pleno en la más típica tradición alejandrina, que ve la fuente de la acción divinia en la historia sobre todo en la $\varphi \imath \lambda \alpha \nu \theta \rho \omega \pi^{i} \alpha^{11}$.

Sin embargo, no solo el ambiente teológico, en el cual vivía Gregorio, influyó en el lenguaje y modo de argumentar en sus principales posiciones cristológicas. La producción literaria de nuestro autor nos deja vislumbrar la influencia del contexto social, que se concretiza en la educación y formación recibidas. Gracias a una profunda educación moral y una excelenete formación intelectual, el Niceno en sus obras presenta un alto nivel del saber filosófico, médico y teológico ${ }^{12}$. Hay que ver un elemento muy importatnte, que podia influir en la doctrina critológica de Gregorio, en el hecho de haber recibido la formación retórica, gracias a la cual, en su actividad apológetica, podía acceder a los recursos de la literatura griega clásica y usar de los instrumentos del discurso, como, por ejemplo, la paradoja ${ }^{13}$. Estas tecnicas encuentran un lugar privilegiado en la más madura obra de Gregorio - In Canticum canticormum. Se puede decir, que en este tratado se encuentra una recapitulación de su pensamiento cristológico, entre otros, a causa de la implementación de la

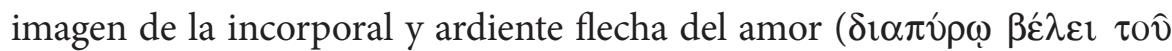

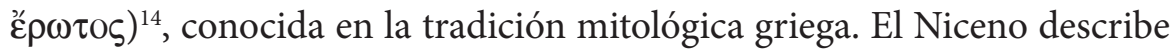
esta flecha como atributo del Christo-Arquero, que hiere al alma con su

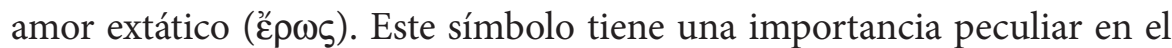

9 Por. H.U. von Balthasar, Presence and Thought. An Essay on the Religious Philosophy of Gregory of Nyssa, San Francisco 1995, s. 165.

${ }^{10}$ Por. Gregorius Nyssenus, Contra Eunomium II, Gregorii Nysseni Opera 2, red. W. Jaeger, Leiden 1960, s. 485.

${ }^{11}$ Por. W. Völker, Zur Gotteslehre Gregors von Nyssa, "Vigiliae Christianae" 1955, nr 9, s 122.

${ }_{12}$ Por. N. Russell, The doctrine of deification in the Greek patristic tradition, Oxford 2006, s. 225.

${ }^{13}$ Por. L.F. Mateo-Seco, Chrystology, s. 150.

14 Por. Gregorius Nyssenus, In Canticum canticorum, Gregorii Nysseni Opera 6, red. H. Langerberck, Leiden 1960, s. 383. 
discurso cristológico de Gregorio, porque expresa la orientación del deseo cristiano hacia la perfección. De hecho, Cristo ocupa un lugar central en corpus literario de Gregorio y por eso tanto su teología como su espiritualidad son radicalmente y enteramente cristocéntricas ${ }^{15}$. Por otra parte, el instrumento muy eficaz de la paradoja sirve al Niceno para localizar la cumbre de la economía divina, que se focaliza en la Encarnación concebiada como kenosis. Basándose en el analisis y la juxtaposición de dos pasajes bíblicos: J 1,1-14 y Flp 2,5-11, Gregorio define la Encarnación como: „abajamiento”; el recibir de algo de la creación por parte de Cristo; epifanía de Dios en la carne, así como la „exaltación” que conduce a la glorificación del cuerpo humano, con el cual el Verbo se unió en su persona. Por medio de esta glorificación del cuerpo por medio de Cristo se efectua la manifestación de la gloria del Padre ${ }^{16}$.

\section{EL CONTEXTO FILOSÓFICO}

En mosaico filosófico, que contienen las obras de Gregorio, constituye la base de la elaboración de su original exposición de la doctrina cristológica. El autor bebe en las ricas fuentes de las diferentes tradiciones filosóficas, sobre todo en el platonismo, estoicismo, neoplatomismo. Sin embargo, en varias ocasiones, nuestro teólogo demuestra su distanciamiento respecto a sus principios. Aunque Gregorio está considerado como un platónico cristiano, la influencia de Platón en su pensamiento cristológico se limita principalmente en el identificar el ser con con lo bueno, lo hermoso y lo verdadero. Dios es el bien supremo y la fuente de todo bien, toda hermosura y toda verdad. Sin embargo en el sistema de Gregorio esta idea encuentra su aplicación tan solo a causa del asemejamiento de Dios respecto a la creación, a la vez guardando a salvo la fundamental distincción ontológica entre el Creador y la creación, que se diluye en el platonismo ${ }^{17}$. Además, la idea del despertar del amor absoluto

15 Por. L.F. Mateo-Seco, Chrystology, s. 139.

16 Por. Gregorius Nyssenus, Contra Eunomium III, s. 152. 300; L.F. MateoSeco, Chrystology, s. 150.

17 Por. M. Ludlow, Plato, w: The Brill Dictionary of Gregory of Nyssa, red. L.F. Mateo-Seco, G. Maspero, Supplements to "Vigiliae Christianae" 99, Leiden 2010, s. 623 . 
a través del conocimiento de la hermosura perfecta, que Gregorio recibe de Platón ${ }^{18}$, le sirve para establecer un modelo dinámico-ontológico del fluir del amor en el seno de la misma Trinidad, cuya extistencia se reali-

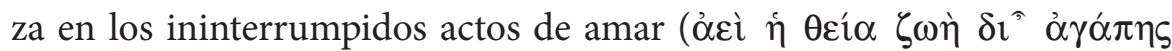

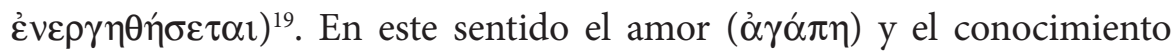
son en el seno de la Trinidad indivisibles y caracterisan la misma vida

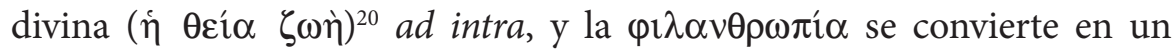
instrumento especial de la revelación ad extra de la intimidad divina, en la que - a través de la obra de la Encarnación - Dios desea incluir también toda la humanidad. También aquí encontramos otra reminiscencia del platonismo, en el cual el objeto del amor se identifica con la posesión eterna del bien ${ }^{21}$. Gregorio transpone esta idea en el ámbito de la actuación de la perfecta hermosura de las Personas de la Trinidad, la cual, como bien verdadero e inagotable, determina el eterno y dinámico fluir del amor.

En este sentido, tanto para Platón, como para Gregorio, la Divinidad es algo muy atractivo. Por esta causa, en los escritos del Niceno los motivos platónicos encuentran una aplicación sobre todo en el tereno de las descripciones del deseo de llegar a la divinidad por parte del hombre y del ascender del alma hacia Dios ${ }^{22}$, que se identifica con las esponsales con $\mathrm{Cristo}^{23}$. Estas prestaciones quedan muy palpables en el tema desarrollado ampliamente por Gregorio bojo el concepto de la divinisación ( $\theta \varepsilon \circ \pi \mathrm{o} \varepsilon \dot{\varepsilon} \omega)$, sustituido en los escritos posteriores por el tema de la participación en Dios ( $\mu \varepsilon \tau o v \sigma i ́ \alpha \theta \varepsilon \circ \widehat{v})^{24}$ para preservar la ortodoxia de la

18 Por. Platon, Uczta, 210e-211b.

19 Por. Gregorius Nyssenus, De anima et resurrectione, Patrologia cursus completus. Series Graeca 46, red. J.P. Migne, Paris 1863, 96.

${ }^{20}$ Por. G. Maspero, Love. $\dot{\alpha} \gamma \alpha \dot{\alpha} \pi \eta$, ع̌ $\rho \omega \varsigma$, w: The Brill Dictionary of Gregory of Nyssa, red. L.F. Mateo-Seco - G. Maspero, Supplements to "Vigiliae Christianae" 99, Leiden 2010, s. 459.

${ }^{21}$ Por. Platon, Uczta 206a.

22 Por. M. Ludlow, Plato, s. 623. Warto porównać: Platon, Fedon 79d i 81a z Gregorius Nyssenus, In Canticum canticorum, s. 333-334 i 410.

${ }^{23}$ Por. Gregorius Nyssenus, In Canticum canticorum, s. 342; J. Daniélou, Platonisme et théologie mistique. Essai sur la doctrine spirituelle de saint Grégoire de Nysse, Paris 1944, s. 214.

${ }^{24}$ Por. M. Ludlow, Divine infinity and eschatology: the limits and dynamics 
teología apofática y para no diluir los términos de la transcendencia de $\operatorname{Dios}^{25}$. A pesar de esto, entre los estudiosos de la herencia espiritual de Gregorio, hay algunos investigadores que no dudaron definirlo principalmente como propagador de la doctrina de la deificación ${ }^{26}$, concebida como un eterno proceso de ascender del hombre hacia la Divinidad. Según el Niceno este proceso no llega nunca a su cumplimiento definitivo a causa de la infinidad del Ser Divino, que siempre supera la etapa actual de la deificación. Aunque no cesan las discusiones en torno a la tesis que postula que Gregorio fue el primer pensador cristiano que introdujo la categoría de la infinidad en el ámbito de la descripción de la naturaleza de Dios, sin embargo la postura del Niceno difiere bastante en este aspecto de la concepción de Platón, porque Gregorio - polemizando con la visión de la perfección que tuviera una determinada y agotable medida, la cual era propia a los filosofos griegos hasta Plotino ${ }^{27}$ - considera la infinidad como un consecuencia positiva de la transcendencia divina y usa de este conclusión para expresar la eterna atracción de Dios ${ }^{28}$. Por eso las heramientas linguisticas prestadas de la tradición filosófica (tanto los conceptos de herencia platónica, como el aparato místico de las antitesis espirituales propio de Filóna i Plotino ${ }^{29}$, utilizados para destacar la infi-

of human knowledge, according to Gregory of Nyssa (CE II, 67-170), w: Contra Eunomium II, An English Version with Supporting Studies Proceedings of the 10 th International Colloquium on Gregory of Nyssa (Olomouc, September 15-18, 2004), red. L. Karfíková, S. Douglass, J. Zachhuber, Vigiliae Christianae Supplements 82, Leiden 2007, s. 234.

${ }^{25}$ Por. N. Russell, The doctrine of deification, s. 232.

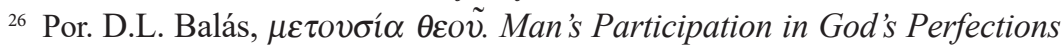
According to Saint Gregory of Nyssa, Studia Anselmiana 55, Rome 1966; D.L. Balás, Christian Transformation of Greek Philosophy Illustrated by Gregory of Nyssa's Use of the Notion of Participation, „Proceedings of the American Catholic Philosophical Association" 1966, nr 40, s. 152-157; B.E. Daley, 'Heavenly Man' and 'Eternal Christ': Apollinarius and Gregory of Nyssa on the Personal Identity of the Savior, ,Journal of Early Christian Studies" 2002, nr 10/4, s. 469-488.

${ }_{27}$ Por. R.E. Heine, Perfection in the virtuos life. A study in the Relationship between Edification and Polemical Theology in Gregory of Nyssa's "De Vita Moysis", Cambridge 1975, s. 71-79.

${ }^{28}$ Por. A. Meredith, Gregory of Nyssa, The early church fathers, London-New York 1999, s. 13; M. Ludlow, Plato, s. 623.

${ }^{29}$ Por. A. Nygren, Agape und Eros. Gestaltwandlungen der christlichen Liebe, 
nidad de Dios) reflejan una procedimiento muy típico de Gregorio - el uso de los elementos de un determinado sistema filosófico con el fin de entablar una polémica con el mismo.

Entre los factores filosóficos, que han determinado la forma definitiva de la doctrina cristológica de Gregorio, un papel considerable jugó la influencia de los autores cristianos y Padres de la Iglesia anteriores a él, principalmente de Ireneo de Lyon, Clemete Alejandrino, Orígeno y Metodio de Olimpio. Sin embargo, fue la doctrina teológico-filosófica de este último, donde Gregorio encontró su principal fuente de inspiración para la elaboración de su concepción realista de la unidad humana. Esta concepción es crucial para la correcta lectura de la cristología gregoriana. Metodio, apoyándose en la teoría de la recapitulación de Ireneo de Lyon, fue un eslabón en la continuación de la doctrina de la solidaridad del género humano, en un cierto sentido estrechando su entendimiento a causa de su concepción realista o mística de la unidad. En su De resurrectione habla de nuestra vida en el Paraíso - no solo en Adán, sino en los ambos progenitores primitivos ${ }^{30}$. Conforme a las opiniones de algunos investigadores modernos ${ }^{31}$, en los pasajes mencionados no se trata de la identificación, sino de una puesta de relieve de la unidad de toda la humanidad, analógicamente a la constatación que en el Adán todos hemos trangredido el mandamiento de $\operatorname{Dios}^{32}$, o en el fragmento que dice, que Cristo se hizo lo mismo con Adán ${ }^{33}$. En este sentido Gregorio interpreta la filiación divina en Cristo como la recapitulación de todo el plan salvífico de Dios, porque en la Encarnación el Verbo „carga sobre sí mismo”, „une a sí mismo” y „asume” la humanidad ${ }^{34}$. Este es el momento de culminación: la kenosis de Cristo, siendo a la vez la exaltación del cuerpo humano, constituye para Gregorio la base no solo para la unión con la naturaleza humana individual, sino para establecer la unidad con toda la humanidad, que en el sistema del Niceno se concibe como una monada. Por este

Berlin 1955, s. 334.

${ }^{30}$ Por. Methodiu, De resurrectione, Leipzig 1917, s. 189.

${ }^{31}$ Por. M. Przyszychowska, Wszyscy byliśmy w Adamie, s. 52.

32 Por. Methodiu, De resurrectione, s. 281.

${ }^{33}$ Por. Methodiu, Symposion ton deka parthenon, Patrologia cursus completus. Series Graeca 18, red. J.P. Migne, Paris 1857, 65-68.

34 Por. L.F. Mateo-Seco, Chrystology, s. 139. 
hecho, la Encarnación, que Gregorio considera como en las categorías de la elevación ${ }^{35}$ y manifestación de la bondad del mundo material, se opone radicalmente a las valoraciones platónicas ${ }^{36}$, y no solo esto: en la Encarnación ocurre justamente el momento de la transmisión a la humanidad de la gracia de la resurrección y de la deificación, que son inaccesibles al hombre según sus propias fuerzas ${ }^{37}$. La posición central del Misterio de la Encarnación en el corpus entero de las obras de Gregorio tiene como finalidad la demostración de la verdad que el fin de la economía divina consiste en la realización de la unión hipostática ${ }^{38}$, que ha de establecerse entre la naturaleza humana individual asumida en la Encarnación por Jesús y la enter monada humana ${ }^{39}$. Esta unión se convierte en la causa efficiens de la transormación desde dentro de la creación ${ }^{40}$. A modo de imagen, la Encarnación está presentada como las premisas de la masa de

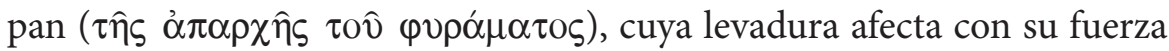

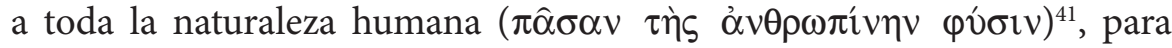
atraer a todo hacia el mismo género - unir a la humanidad entera con la humanidad de Cristo enteramente deificada ${ }^{42}$.

\section{EL CONTEXTO PSICOLÓGICO}

La biografía de Gregorio parece ser también un elemento que influye en la formación de las principales características de su cristología,

35 Por. Gregorius Nyssenus, De instituto Christiano, Gregorii Nysseni Opera 8/1, red. W. Jaeger), Leiden 1963, s. 88; tenże, In Canticum canticorum, s. 304.

${ }^{36}$ Por. M. Ludlow, Plato, s. 624.

${ }^{37}$ Por. H.U. von Balthasar, Presence and Thought, s. 134-135; L. Malavez, L'Église dans le Christ, „Recherches de science religieuse” 25 (1935), s. 257-297.

${ }^{38}$ Por. G. Maspero, Philantropia, s. 599.

39 Por. J. Gross, La divinisation du chrétien d'après les Pères Grecs. Contribution historique a la doctrine de la grâce, Paris 1938; J.R. Bouchet, La vision de l'économie du salut selon saint Grégoire de Nysse, „Recherches des Sciences Philosophiques et Theologiques" 52 (1968), s. 613-644.

${ }^{40}$ Por. E. Kotkowska, Nauczanie św. Grzegorza z Nyssy o wszechmocy Bożej na podstawie In illud: Tunc ipse Filius, „Vox Patrum” 24 (2004), s. 511-526, s. 521.

${ }^{41}$ Por. Gregorius Nyssenus, In Canticum canticorum, s. 427-428.

${ }^{42}$ Por. Gregorius Nyssenus, De perfectione Christiana ad Olympium monachum, Gregorii Nysseni Opera 8/1, red. W. Jaeger, Leiden 1963, s. 204-205. 
sobre todo las que se relacionan dirrectamente con la espiritualidad. El autor ya desde su tierna edad fue muy sensible a las realidades de índole espiritual y nutría un interés muy fuerte hacia la busqueda filosófica.

Educado en la familia que dio a la Iglesia a los siete santos ${ }^{43}$, a pesar de la fascinación por la espiritualidad y las inclinaciones hacia la vida ascética, escogió, siguiendo a su padre, la carrera de retor y contrajo el matimonio con Teosebia. Sin embargo, siguiendo después el consejo de sus amigos, sobre todo de san Gregorio Nacianzeno, se inclinó hacia la vida monástica en el centro monástico fundado por su hermano Basilio a las orillas del río Iris en el país de Ponto ${ }^{44}$. Esta mudanza en la vida de Gregorio parece conllevar consigo unas consecuencias serias en su doctrina, que se manifiestan sobre todo en su espiritualidad contemplativa y su visión de la sensualidad.

La espiritualidad contemplativa de Gregorio se focalisa en la adoración y la exemplificación de los nobres de Cristo. Él, siendo obediente a la voluntad del Padre, sin perder nada de su divinidad, a causa del amor hacia el hombre asumió un abajamiento voluntario i se convirtio en la imagen visible del Dios invisible para manifestar a la humanidad un modelo de santidad ${ }^{45}$ : Proponiendo los nombres que pertenecen tanto a la divinidad, como a la humanidad del Señor, entre los cuales hay que enumerar „Esplendor de la gloria de Dios”, „Poder y Sabiduría de Dios”, „Primogénito entre los muertos”, o "Sacerdote, propiciatorio y Pasqua”, Gregorio expresa su convicción que el hombre, uniéndose a Cristo en el acto de la contemplación, queda también unido con su divinidad. Así queda demostrado uno de los caminos de la deificación, porque - segú nuestro autor - el hombre siendo creado a la imagen y semejanza de Dios encuentra la salvación en la unión con Él, que es la Imagen perfecta del Padre $^{46}$. La contemplación concebida de este modo conduce a Gregorio a considerar la necesidad de la purificación del „ojo del alma” ${ }^{47}$, como

${ }^{43}$ Por. W. Kania, Nienasycona nigdy tęsknota za Bogiem, Tarnów 1994, s. 11.

${ }_{44}$ Por. F. Drączkowski, Partologia, Pelplin - Lublin 2007, s. 239.

${ }^{45}$ Por. Gregorius Nyssenus, De perfectione Christiana ad Olympium monachum, S. 195.

46 Por. L.F. Mateo-Seco, Chrystology, s. 145.

${ }^{47}$ Por. Gregorius Nyssenus, In Canticum canticorum, s. 106-107. 
un medio para intensificar el progreso de la deificación. Finalmente, esta concepción parece ser un eco del Simposion i Phaedrus de Platón, así que de la sección novena de las Enneadas de Plotino ${ }^{48}$. Sin embargo, estas consideraciones han llevado a Gregorio a establecer la primera e integra descripción de las etapas sucesivas del desarrollo de la vida espiritual del creyente, que encuentra su meta en la unión con Cristo. Esta descripción, junto al concepto de la infinidad divina, determinante para el proceso del infinito crecimiento o la infinita participación en la divinidad, han sido universalmente recibidos como bases de la mística cristiana $^{49}$.

Apoyándose en la investigación de Sarah Coakley sobre la transfiguración de los sentidos espirituales en la doctrina de nuestro autor ${ }^{50}$, se puede aceptar la tesís de la teoría evolutiva de los sentidos, la cual con la experiencia cada vez mayor de Gregorio iba adquiriendo unas dimensiones cada vez más originales, librándose poco a poco de las dependencias platónicas, sin lograrlo nunca del todo en el caso del Niceno. El criterio de división adopotado por S. Coakley se basa en las dos linias de demarcación: la muerte de los hermanos de Gregorio (Basilio y Macarina) por una parte, y un cada vez más rico conocimiento de las capacidades corporales en el proceso de transformación como consecuencia de la Encarnación, Resurrección y del Pentecostés por otra. Por eso las tempranas obras de Gregorio quedan bajo la impronta de la división platónica entre el cuerpo y la mente, mientras que el cambio mental (producido por una meditación profundamente nutrida sobre el fenomeno de la mortalidad), implica una progresiva apreciación de los sentidos por el Niceno respecto a la posibilidad de anudar una relación íntima y casí de proximidad erótica con Cristo. Esto demuestra una progresiva evolución en cuanto a la valoración de la importancia de la vida corporal respecto a la recep-

${ }^{48}$ Por. A. Meredith, Neoplatonism, w: The Brill Dictionary of Gregory of Nyssa, red. L.F. Mateo-Seco, G. Maspero, Supplements to "Vigiliae Christianae" 99, Leiden 2010, s. 531-532.

${ }^{49}$ Por. J. Daniélou, Platonisme et théologie mystique, 6; M. Ludlow, Divine infinity and eschatology: the limits and dynamics of human knowledge, according to Gregory of Nyssa (CE II, 67-170), s. 234.

${ }^{50}$ Por. S. Coakley, Grzegorz z Nyssy, w: Duchowe zmysty. Percepcja Boga w zachodnim chrześcijaństwie, red. P.L. Gavrilyuk - S. Coakley, Kraków 2014, s. 57-80. 
tividad espiritual de los sentidos ${ }^{51}$. Este cambio tuvo su efecto tembién en el nivel pragmático de la visión del desarrollo del hombre a través de la valoración cada vez más fuerte de los aspectos cognitivos, éticos y ascéticos por Gregorio. En consecuencia, nuestro autor cada vez más frecuentamente pondrá en tela de juicio los principios platónicos respecto a la corporiedad. A diferencia de Orígenes, que hace uso de las metaforas corporales y eróticas para describir la relación del alma con Cristo con una precaución más notable, el Niceno deja atrás las dicotomías platónicas para poner de relieve la exaltación del disfrute positivo de los sentidos espirituales $^{52}$. Las referencias pintorescas hechas a su respecto se basan en las experiencias de los sentidos corporales, que no quedan más bajo el tenebroso regimen del pecado, sino - como constata Jean Daniélou los sentidos inferiores, cuando son transformados y purificados, parecen finalmente soportar sin guerra los sentidos superiores ${ }^{53}$.

\section{CONCLUSIONES}

La presentación de la triple tipología de los factores que influyeron en el pensamiento de Gregorio de Nisa indica un grado elevado adquirido por el autor en cuanto a la clarida y la concisión de la exposición de la doctrina cristológica contenida en sus obras, a pesar del uso de la terminología todavía in fieri en los tiempos del santo.

Su sólida formación retórica, continuación de la teología apofática, así que un distanciamiento cada vez más pronunciado respecto al discurso platónico, constituyen las principales características del pensamiento cristológico del teólogo de Nisa, intrínseco de su soteriología y concepción mística. Gracias a una muy original y precisa determinación de tres etapas del desarrollo de la reación personal del creyente con Cristo, Gregorio ejerció una influencia y autoridad considerables en los autores cristianos posteriores, como san Juan de la Cruz o Hans Ursa

${ }^{51}$ Por. J. Daniélou, La chronologie des oeuveres de Grégoire de Nysse, „Studia Patristica" 7 (1966), s. 159-169.

52 Por. S. Coakley, Grzegorz z Nyssy, s. 76-78.

${ }^{53}$ Por. J. Daniélou, Platonisme et théologie mistique, s. 242-252. 
von Balthasara, fijándo las bases del entendimiento de la mística cristiana fiel a la ortodoxia. También su valoración de los recursos filosóficos en la exposición de la fe tuvo una gran repercusión en la posterioridad, sirviendo útilmente al mismo Gregorio para elaborar y precisar la idea de la unidad de toda la humanidad en sus detalles. El contexto propio para entender bien la cristología de nuestro autor se basa en su concepción realista de la monada humana, elaborada en analogía a la descripción de la Natura Divina (una natura - tres hipostasis). Esta unidad tiene que ser considerada como un factor unitivo (soldadura), por medio del cual - según Gregorio - ha sido iniciada un conexión peculiar entre la natura humana individual, asumida personalmente por Cristo en la Encarnación, y toda la humanidad, que - en consecuencia de la unión hipostática - participa en todos los frutos de la Redención. Aquí estamos ante el meollo y culmen de toda la cristología del Niceno, donde encuentra ella su común denominador expresado en dos términos: „humanización” y „divinización”.

Streszczenie. Artykuł Chrystologia św. Grzegorza z Nyssy. Doktryna i kontekst prezentuje trzy podstawowe faktory stymulujące powstanie doktryny chrystologicznej św. Grzegorza z Nyssy: kontekst społeczny, filozoficzny i psychologiczny. Staranne wykształcenie retorskie, kontynuacja tradycji teologii apofatycznej oraz stopniowe dystansowanie się od dyskursu platońskiego, stanowią główne czynniki konfigurujące chrystologię Autora, pozostającą w nierozerwalnym związku z soteriologią i mistyką. Faktory te ukazują wpływ na uformowanie się kluczowej dla Grzegorza idei jedności całej ludzkości. Monada ta kluczowym spoiwem, poprzez które ustanowiona została łączność pomiędzy przyjętą przez Chrystusa we Wcieleniu jednostkową, indywidualną naturą ludzką a całą ludzkością. Jest to więc moment kulminacyjny całej chrystologii Nysseńczyka, wyrażającej się w dwóch podstawowych terminach: „humanizacji” i „przebóstwienia”.

Słowa kluczowe: chrystologia; kontekst; wykształcenie; filozofia; duchowość.

Abstract. The article Christology of Gregory of Nyssa. Doctrine and Context presents three basic factors stimulating origins of St. Gregory's of Nyssa christological doctrine - social, philosophical and psychological context. Good rhetoric education, continuation of apophatic theology's traditions and progressive distancing of Platonic discourse are the main elements configuring the author's Christology, which remains in inseparable connection with soteriology and mysticism. These factors show the impact on the formation of the idea of all mankind's unity, which is crucial for St. Gregory. This 
monad is the fundamental binder which combines adopted by Christ in the Incarnation, unitary, individual human nature with all mankind. So this is the culmination of the whole Christology of the Nyssian, expressed in two basic terms - 'humanisation' and 'deification'.

Keywords: Chrystology; Context; Education; Philosophy; Spirituality.

\section{BIBLIOGRAFÍA}

Gregorius Nyssenus, Ad Ablabium quod non sint tres dei, Gregorii Nysseni Opera 3/1, red. F. Mueller, Leiden 1958, s. 37-57.

Gregorius Nyssenus, Contra Eunomium, Gregorii Nysseni Opera 1-2, red. W. Jaeger, Leiden 1960.

Gregorius Nyssenus, De anima et resurrectione, Patrologia cursus completus. Series Graeca 46, red. J.P. Migne, Paris 1863, k. 12-160.

Gregorius Nyssenus, De deitate Filii et Spiritus Sancti, Patrologia cursus completus. Series Graeca 46, red. J.P. Migne, Paris 1863, k. 553-576.

Gregorius Nyssenus, De instituto Christiano, Gregorii Nysseni Opera 8/1, red. W. Jaeger, Leiden 1963, s. 40-89.

Gregorius Nyssenus, De perfectione Christiana ad Olympium monachum, Gregorii Nysseni Opera 8/1, red. W. Jaeger, Leiden 1963, s. 173-214.

Gregorius Nyssenus, In Canticum canticorum, Gregorii Nysseni Opera 6, red. H. Langerberck, Leiden 1960.

Gregorius Nyssenus, Oratio catechetica magna, Gregorii Nysseni Opera 3/4, red. E. Mühlenberg, Leiden 1996.

Methodiu, De resurrectione, Leipzig 1917.

Methodiu, Symposion ton deka parthenon, Patrologia cursus completus. Series Graeca 18, red. J.P. Migne, Paris 1857, k. 27-217.

Platon, Uczta, Kęty 2007.

Balás D.L., Christian Transformation of Greek Philosophy Illustrated by Gregory of Nyssa's Use of the Notion of Participation, „Proceedings of the American Catholic Philosophical Association” 1966, nr 40, s. 152-157.

Balás D.L., metous... a qeoũ. Man's Participation in God's Perfections According to Saint Gregory of Nyssa, Studia Anselmiana 55, Rome 1966.

Balthasar H.U. von, Presence and Thought. An Essay on the Religious Philosophy of Gregory of Nyssa, San Francisco 1995.

Boersma H., Embodiment and Virtue in Gregory of Nyssa. An Anagogical Approach, Oxford 2013.

Bouchet J.R., La vision de l'économie du salut selon saint Grégoire de Nysse, „Recherches des Sciences Philosophiques et Theologiques” 1968, nr 52, s. 613-644. 
Coakley S., Grzegorz z Nyssy, w: Duchowe zmysty. Percepcja Boga w zachodnim chrześcijaństwie, red. P.L. Gavrilyuk - S. Coakley Kraków 2014, s. 57-80.

Daley B.E., 'Heavenly Man' and 'Eternal Christ': Apollinarius and Gregory of Nyssa on the Personal Identity of the Savior, „Journal of Early Christian Studies” 2002, nr $10 / 4$, s. $469-488$.

Daniélou J., La chronologie des oeuveres de Grégoire de Nysse, „Studia Patristica” 1966, nr 7, s. 159-169.

Daniélou J., Platonisme et théologie mistique. Essai sur la doctrine spirituelle de saint Grégoire de Nysse, Paris 1944.

Drączkowski F., Partologia, Pelplin-Lublin 2007.

Gross J., La divinisation du chrétien d'après les Pères Grecs. Contribution historique a la doctrine de la grâce, Paris 1938.

Heine R.E., Perfection in the virtuos life. A study in the Relationship between Edification and Polemical Theology in Gregory of Nyssa's „De Vita Moysis”, Cambridge 1975.

Kania W., Nienasycona nigdy tęsknota za Bogiem, Tarnów 1994.

Kotkowska E., Nauczanie św. Grzegorza z Nyssy o wszechmocy Bożej na podstawie In illud: Tunc ipse Filius, „Vox Patrum” 2004, nr 24, s. 511-526.

Ludlow M., Divine infinity and eschatology: the limits and dynamics of human knowledge, according to Gregory of Nyssa (CE II, 67-170), w: Contra Eunomium II, An English Version with Supporting Studies Proceedings of the $10^{\text {th }}$ International Colloquium on Gregory of Nyssa (Olomouc, September 15-18, 2004), red. L. Karfíková, S. Douglass, J. Zachhuber, Vigiliae Christianae Supplements 82, Leiden 2007, s. 217-237.

Ludlow M., Plato, w: The Brill Dictionary of Gregory of Nyssa, red. L.F. Mateo-Seco, G. Maspero, Supplements to Vigiliae Christianae 99, Leiden 2010, s. 623-625.

Malavez L., L'Église dans le Christ, „Recherches de science religieuse” 1935, nr 25, s. 257-297.

Maspero G., Love. $₫ g £ p h$, «rwj, w: The Brill Dictionary of Gregory of Nyssa, red. L.F. Mateo-Seco, G. Maspero, Supplements to Vigiliae Christianae 99, Leiden 2010, s. $457-463$.

Maspero G., Philantropia, w: The Brill Dictionary of Gregory of Nyssa, red. L.F. Mateo-Seco, G. Maspero, Supplements to Vigiliae Christianae 99, Leiden 2010, s. 597-600.

Mateo-Seco L.F., Chrystology, w: The Brill Dictionary of Gregory of Nyssa, red. L.F. Mateo-Seco, G. Maspero, Supplements to Vigiliae Christianae 99, Leiden 2010, s. $139-152$.

Meredith A., Gregory of Nyssa, The early church fathers, London-New York 1999.

Meredith A., Neoplatonism, w: The Brill Dictionary of Gregory of Nyssa, red. L.F. Mateo-Seco, G. Maspero, Supplements to Vigiliae Christianae 99, Leiden 2010, s. $531-532$.

Nygren A., Agape und Eros. Gestaltwandlungen der christlichen Liebe, Berlin 1955. 
Russell N., The doctrine of deification in the Greek patristic tradition, Oxford 2006.

Przyszychowska M., Wszyscy byliśmy w Adamie. Jedność ludzkości w Adamie w nauczaniu ojców Kościoła, Poznań 2013.

Strękowski S., Sofiologia św. Grzegorza z Nyssy: elementy teologii trynitarnej i antropologii w „Homiliach do Pieśni nad Pieśniami”, Kraków 2006.

Völker W., Zur Gotteslehre Gregors von Nyssa, „Vigiliae Christianae” 1955, nr 9, s. 103-128. 